Société d'histoire de la révolution de 1848 et des

révolutions du XIXe siècle

Relations sociales et espace public

Hélène Blais, Voyages au grand océan. Géographies du Pacifique et colonisation, 1815-1845, Paris, Éditions du CTHS, 2005, 351 p. ISBN : 2-7355-0588-X. 58 euros.

\title{
Sylvain Venayre
}

\section{CpenEdition}

\section{Journals}

Édition électronique

URL : http://journals.openedition.org/rh19/1180

DOI : $10.4000 /$ rh 19.1180

ISSN : $1777-5329$

Éditeur

La Société de 1848

Édition imprimée

Date de publication : 1 décembre 2006

Pagination : 169-232

ISSN : 1265-1354

\section{Référence électronique}

Sylvain Venayre, « Hélène Blais, Voyages au grand océan. Géographies du Pacifique et colonisation, 1875-1845, Paris, Éditions du CTHS, 2005, 351 p. ISBN : 2-7355-0588-X. 58 euros. », Revue d'histoire du XIXe siècle [En ligne], 33 | 2006, mis en ligne le 03 novembre 2008, consulté le 22 septembre 2020. URL : http://journals.openedition.org/rh19/1180 ; DOI : https://doi.org/10.4000/rh19.1180 


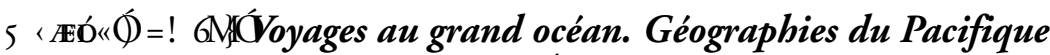
et colonisation, 1815-1845, Paris, Éditions du CTHS, 2005, 351 p. ISBN : 2-7355-0588-X. 58 euros.

De 1817 à 1840, onze voyages ont été effectués par des équipages de la Marine française à travers l'Océan Pacifique. Financés et organisés par le ministère de la Marine et des Colonies, correspondant à une politique de prestige cherchant à redorer le blason d'une Marine qui s'était lamentablement comportée pendant les guerres de la Révolution et de l'Empire, ces expéditions croisèrent celles des Russes, des Anglais, voire des Américains présents dans les parages au même moment. En 1840, le second retour en France de Dumont d'Urville marqua la fin d'une époque : celle des grandes circumnavigations à la voile. En 1842, la mission de Dupetit-Thouars aux Marquises, prolongée en direction de Tahiti à l'initiative du commandant de la nouvelle Station navale du Pacifique, ouvrit une nouvelle ère : celle de la colonisation.

C'est cet intervalle de temps, finalement peu connu, pris en tenaille entre les grands voyages de circumnavigation de la fin du XviII ${ }^{e}$ siècle et la modernité coloniale du second $\mathrm{XIX}^{\mathrm{e}}$ siècle, qu'Hélène Blais a choisi d'analyser dans le cadre de sa thèse, dont Voyages au grand océan constitue la version éditoriale - une version somptueuse, chère et notablement illustrée. De ce travail d'une très grande rigueur, alliant le goût du détail d'archive à une maitrise remarquable de la bibliographie, tout entier placé sous les auspices de cette histoire sociale et culturelle des sciences qui multiplie, depuis plusieurs années, les travaux d'une qualité exceptionnelle, on soulignera ici deux grands axes.

Le premier concerne les renouvellements subis, dans la première moitié du XIX ${ }^{e}$ siècle, par la figure du "voyageur philosophe" chère à Rousseau et qu'avaient notamment magnifiée, à partir des années 1760, les expéditions scientifiques autour du monde de Bougainville, Cook et Lapérouse. Dans le cadre de l'Océan Pacifique du premier XIx ${ }^{e}$ siècle, en effet, le modèle de la «découverte» tendait à devenir obsolète. À l'exception de ce qui concernait le pôle, il n'y avait là-bas presque plus de terres à découvrir et les marins exprimèrent volontiers leur sentiment de venir après que les grandes choses eurent été faites, ainsi que leur désappointement face à une nature qu'ils avaient cru paradisiaque. Autre renouvellement, conséquence de l'échec de l'expédition Baudin (1800-1804) : l'absence de personnels civils à bord de ces navires, qui promut les officiers de marine en responsables directs de l'observation scientifique - avec une conséquence immédiate : le rôle accru, dans l'encadrement des expéditions maritimes, des savants stationnés à Paris. Hélène Blais, qui ne s'intéresse ici qu'aux disciplines relevant de la science géographique en constitution, omettant tout ce qui relève de l'anthropologie, consacre ainsi de longs développements au rôle fondamental joué par les institutions 
centrales (Académie des sciences, Observatoire, Dépôt des cartes et plans), aux instructions aux voyageurs, rédigées le plus souvent par les membres de ces institutions, aux instruments de mesure (boussoles, thermomètres, baromètres, lignes de sonde, etc), dont les usages normés disent la méfiance des savants vis-à-vis des marins tout autant que leur célébration de l'exactitude mathématique. Elle analyse aussi la difficulté à appliquer ces instructions et à utiliser ces instruments dans les conditions du voyage, ainsi que la concurrence de légitimité entre les savants sédentaires et les officiers voyageurs, à l'image des relations orageuses entre Arago et Dumont d'Urville. Une tension constitutive de la science du XIX ${ }^{e}$ siècle est ainsi mise en évidence, entre le désir de standardisation et la nécessité de la parole d'un témoin particulier; et l'on ne peut que souscrire au jugement d'Hélène Blais lorsqu'elle écrit que «le voyage est l'un des lieux où apparait alors clairement cette tension».

Le second axe du travail d'Hélène Blais concerne le rôle exact joué par la quête de savoir scientifique dans le processus ayant conduit à la décision de coloniser. De ce débat complexe, très avancé dans l'historiographie angloaméricaine et que la thèse récente d'Emmanuelle Sibeud a présenté pour le cas de l'Afrique française de la fin du XIX ${ }^{\mathrm{e}}$ siècle ${ }^{15}$, Hélène Blais propose une approche toute en nuances, loin des schémas réducteurs qui soit exonèrent les scientifiques de toute "responsabilité" dans le processus de colonisation, soit identifient tout savoir en constitution à un désir de pouvoir. D'une part, en effet, elle souligne la lenteur et les modalités complexes de la diffusion des savoirs géographiques rapportés par les officiers de marine : les comptes rendus des expéditions paraissent échelonnés sur des décennies, n’accédant au grand public cultivé que sous la forme biaisée de la vulgarisation, compliquant d'autant la pénétration dans la société française d'une hypothétique «idée coloniale». D'autre part, si les descriptions des officiers, avec des différences notables selon les hommes et les lieux, soulignent toutes le potentiel des îles auxquelles ils abordent, les espaces finalement colonisés par les Français, de Tahiti à la Nouvelle-Calédonie, ne furent pas ceux que les officiers de marine avaient eux-mêmes suggérés dans leurs rapports. Cette analyse subtile conduit d'ailleurs le lecteur à regretter qu'Hélène Blais n'ait pas choisi d'employer, à propos de la "colonisation", le même pluriel qui lui fait analyser, très justement, «les géographies». Abordant par exemple la question, fondamentale pour le Pacifique, de la colonisation pénitentiaire, Hélène Blais montre bien les singularités de ce discours colonialiste original et des oppositions qu'il a engendrées. Si l'on songe au souvenir que l'on avait alors de l'ancien empire colonial français et de la guerre d'indépendance américaine, ainsi qu'au modèle créé par les récentes conquêtes anglaises, à commencer par les Nouvelles Galles du Sud, ou au débat colonial de l'époque sur l'Algérie, il

15. Emmanuelle Sibeud, Une science impériale pour l'Afrique? La construction des savoirs impérialistes en France, 1878-1930, Paris, Éditions de l'ÉHÉSS, 2002, 356 p. 
semble en effet que l'étude des origines des entreprises coloniales gagnerait en clarté en renonçant à l'idée d'une essence unique de la "colonisation", de la même façon que l'histoire des sciences géographiques a tant gagné en renonçant à projeter dans le passé l'idée d'une seule "géographie».

\section{Sylvain VenAyre}

\section{Craig WILCOX, Autralia's Boer War. The War in South Africa,} 1899-1902, Oxford/New York, Oxford University Press, 2002, 541 p. ISBN : 0195516370. 25 livres sterling.

Le travail mené par l'historien australien Craig Wilcox, auteur en 1993 d'une thèse sur l'armée australienne de 1889 à 1914, s'efforce de restituer les modalités de l'expérience de guerre des soldats australiens pendant la guerre des Boers entre 1899 et 1902 . Fondé sur un dépouillement des principaux dépôts d'archives publiques britanniques, australiennes et sud-africaines auxquelles il faut ajouter des archives privées ainsi que l'abondante presse qui rendit compte des hostilités, cette enquête menée à l'instigation de l'Australian War Memorial jette la lumière sur la participation de quelque 20000 hommes et 80 femmes à une guerre dont les buts leur étaient a priori fort étrangers. L'auteur montre que le contingent, formé pour l'essentiel de volontaires et d'une minorité d'appelés auxquels vinrent se joindre sur place des soldats irréguliers, combattit aux côtés de l'armée britannique dans une guerre qui prit rapidement un tour radical. Les Australiens, tout comme les soldats britanniques, sud-africains, canadiens et néo-zélandais présents pendant ce conflit, participèrent contre leurs ennemis boers à une guérilla qui reprenait les pratiques de guerre coloniales, mais contre un ennemi européen. Il montre aussi comment ce conflit fut la première guerre menée par les Australiens et qu'elle constitua une étape décisive dans le processus de construction de la nation australienne. Il montre enfin comment les jeunes Australiens s'engagèrent pour des raisons ethniques, culturelles et aussi pour préserver les avantages, pas seulement matériels, de leur appartenance à l'immense Empire britannique. Il éclaire ainsi, indirectement, les racines de l'engagement massif des Australiens sur le continent européen pendant la Grande Guerre en montrant l'importance des liens formés entre les membres de l'Empire britannique au cours du XIx siècle.

Odile Roynette 